\title{
SONOGRAPHIC ASSESSMENT OF UTERINE LEIOMYOMA AMONG PREGNANT WOMEN.
}

1. MID (Medical Imaging Doctor) Student

The University of Lahore.

2. MID (Medical Imaging Doctor)

Student

The University of Lahore.

3. MBBS, DMRD, MSc Ultrasound HOD FAHS,

UIRSMIT, University of Lahore.

4. Ph.D. Ultrasound (Scholar), MS Ultrasound (Gold Medalist)

Assistant Professor UIRSMIT

University of Lahore.

Correspondence Address:

Dr. Munaza Shahid

The University of Lahore.

munazashahid73@gmail.com

Article received on:

19/02/2020

Accepted for publication:

02/05/2020

\begin{abstract}
Munaza Shahid', Hafiza Iqra Kanwal ${ }^{2}$, Sajid Shaheen Malik ${ }^{3}$, Raham Bacha ${ }^{4}$
ABSTRACT... Objectives: To sonographically assess uterine leiomyoma among pregnant women. Study Design: Cross-sectional Descriptive study. Setting: Gilani Ultrasound Center, Ferozepur Road Lahore. Period: Sep to Dec 2019. Material \& Methods: The sample size was all the pregnant women with fibroid. Ultrasound machine Honda 2000 HS and Toshiba xerio X4 were used. Results: Out of 73 patients, $47(64.4 \%)$ had fibroid at the anterior wall of the uterus, $14(19.2 \%)$ patients had fibroid at the posterior wall of the uterus, $5(6.8 \%)$ patients had submucosal fibroid, $2(2.7 \%)$ patients had fibroid in the lateral wall of the uterus, $2(2.7 \%)$ patients had fibroid at fundal region of the uterus and $1(1.4 \%)$ of each had fibroid in cervix, lower uterine segment and subserosal. Conclusion: The findings of this study concluded that the anterior wall of the uterus is more favorable for leiomyoma in pregnant women.
\end{abstract}

Key words: Leiomyoma, Pregnancy, Ultrasound.

Article Citation: Shahid M, Kanwal HI, Malik SS, Bacha R. Sonographic assessment of uterine leiomyoma among pregnant women. Professional Med J 2020; 27(9):1902-1905. DOI: 10.29309/TPMJ/2020.27.09.4302

\section{INTRODUCTION}

Leiomyomas also referred to as fibroids or myomas, are the most common gynaecological tumours. These constitute benign tumours of smooth-muscular layer of the uterus. ${ }^{1,2,3}$ Approximately $25-35 \%$ women of reproductive age have fibroid uterus. ${ }^{4}$ Actual incidence of fibroids or myomas is yet unknown but ranges from $0.1 \%-12.5 \% .^{5}$ In African-origin women community, the development of myomas or fibroids at earlier age is common phenomenon. ${ }^{6}$ Usually, leiomyomas are asymptomatic but sometimes can be symptomatic. The most common symptoms are menorrhagia, pain, red degeneration, twisting of pedunculated fibroid and intermenstrual bleeding. The most common complications of leiomyoma are anemia (due to menorrhagia), infertility and miscarriages. ${ }^{7}$

Leiomyomas or myomas can either be single, or multiple in numbers and can also differ in perfusion, location and size. Intramural leiomyoma, the most common, develops within the muscular uterine wall. Subserosal leiomyoma develops on the outer uterine wall. As they grow larger, they can cause pain and pressure on the nearby organ. Submucosal leiomyoma grows just underneath the lining of the uterine cavity. Heavy bleeding and various other serious complications are affiliated with it. Pedunculated leiomyoma develops on the smaller stalks outside or inside the uterus. ${ }^{8,9}$

Incidence of leiomyoma have been reported to $1-5 \%$ during pregnancy. $^{9}$ Its incidence increases with maternal age $>35$ years old and in nulliparous. ${ }^{10}$ Leiomyomas are usually asymptomatic during pregnancy but sometimes can negatively affect pregnancy outcome. Their presence has been linked to difficulty conceiving, spontaneous abortion, placental abruption, preterm birth, cesarean birth, malposition of fetus, dysfunctional labour, intrauterine growth restriction. ${ }^{11}$ The influence of leiomyomas on pregnancy is very much dependent on their type, number, size and location. Females with multiplefibroids have higher miscarriage rate (i.e., 23.6\%) than females with just one fibroid (i.e., $8 \%$ ). In early pregnancy, bleeding chances are much higher if placenta implantation is adjacent to fibroids (i.e., 
$60 \%)$ than the pregnancy where placenta and fibroid have no direct contact (i.e., 9\%). ${ }^{12}$ Fibroids are more common in multi-gravid as compared to primi-gravidae. $.^{9} 15-30 \%$ of leiomyomas may enlarge in the first trimester of pregnancy due to an early response to estrogen, mostly fibroids remain unchanged or reduced in size in the $2^{\text {nd }}$ and $3^{\text {rd }}$ trimester. ${ }^{13}$

Ultrasound is considered to be initial best option for diagnosis of pregnancy and leiomyoma. ${ }^{14,15}$ Ultrasonography either transabdominal or transvaginal is widely used because it is noninvasive, safe, easily available, quick and costeffective. It is considered as the third arm of a gynaecologist. The accuracy and efficacy of ultrasound in the management and diagnosis of uterine leiomyomas have been acknowledged. ${ }^{15}$ Ultrasound is considered helpful for assessment of growth, location and number of fibroids. ${ }^{16}$ Study was conducted to justify the association of leiomyoma with pregnancy for the early diagnosis and management planning. In order to reduce the number of unfavourable outcomes of pregnancy associated with leiomyoma.

\section{MATERIAL \& METHODS}

This descriptive cross-sectional study was conducted at Gilani ultrasound center Lahore from Sep to Dec 2019. The study was conducted after taking ethical approval from university. All women were informed about its purpose and informed consent form was signed by each individual who participated in this study. The sample size was 73 according to the prevalence of the uterine leiomyoma with pregnancy is $1-5 \% .{ }^{9}$ All pregnant women aged 18-40 years with fibroids were consecutively enrolled. Whereas non-pregnant women or women who did not provide signed informed consent were excluded.Ultrasonography was performed via Toshiba (Xario) and Honda 2000 HS with convex array probe, frequency range 3-5 $\mathrm{MHz}$. The transabdominal scan was performed to evaluate the location and size of the fibroids. Women with 1st trimester were scanned with filled bladder while for 2nd and 3rd trimester patients scanned with empty bladder. Statistical analysis was performed using SPSS version 24 . The quantitative variables like age, gestational age, parity, gravidity, and number of fibroids were assessed by using mean, standard deviation and standard errors. The qualitative variables like the location of the fibroid is presented by frequencies and percentages.

\section{RESULTS}

A total of 73 pregnant women with fibroid were included in this study. The mean age of patients was $27.8356 \pm 4.60077$ years with a minimum age of 18 years and maximum age of 40 years. The mean gestational age was 101.602 \pm 56.64037 days with minimum and maximum gestational age as 30 and 252 days. The mean length of fibroid was $3.7438 \pm 1.84346 \mathrm{~cm}$ with minimum and maximum length as 0.40 and $8.8 \mathrm{~cm}$ respectively. The mean width of fibroid was $2.8877 \pm 1.71383 \mathrm{~cm}$ with minimum width as $0.70 \mathrm{~cm}$ and maximum width as $9.6 \mathrm{~cm}$.

\begin{tabular}{|l|c|c|}
\hline Location of Fibroid & Frequency & Percent \\
\hline Anterior wall & 47 & 64.4 \\
\hline Cervix & 1 & 1.4 \\
\hline Fundus & 2 & 2.7 \\
\hline Lateral wall & 2 & 2.7 \\
\hline Lower uterine & 1 & 1.4 \\
\hline Posterior wall & 14 & 19.2 \\
\hline Submucosal & 5 & 6.8 \\
\hline Subserosal & 1 & 1.4 \\
\hline Total & 73 & 100.0 \\
\hline \multicolumn{2}{|c|}{ Table-I. Frequency and percentage of location of the } \\
\end{tabular}

$47(64.4 \%)$ patients had fibroid at the anterior wall of the uterus, $14(19.2 \%)$ patients had fibroid at the posterior wall of the uterus, $5(6.8 \%)$ patients had submucosal fibroid, 2(2.7\%) patients had fibroid in the lateral wall of the uterus, 2(2.7\%) patients had fibroid at fundal region of the uterus and $1(1.4 \%)$ of each had fibroid in cervix, lower uterine segment and subserosal as shown in Table-l.

Out of 73 patients, 14(19.2\%) patients had 1 parity, $18(24.7 \%)$ patients had 2 parity, 22(30.1\%) patients had 3 parity, 16(21.9\%) patients had 4 parity and $3(4.1 \%)$ patients had 5 parity as shown in Figure-1. 


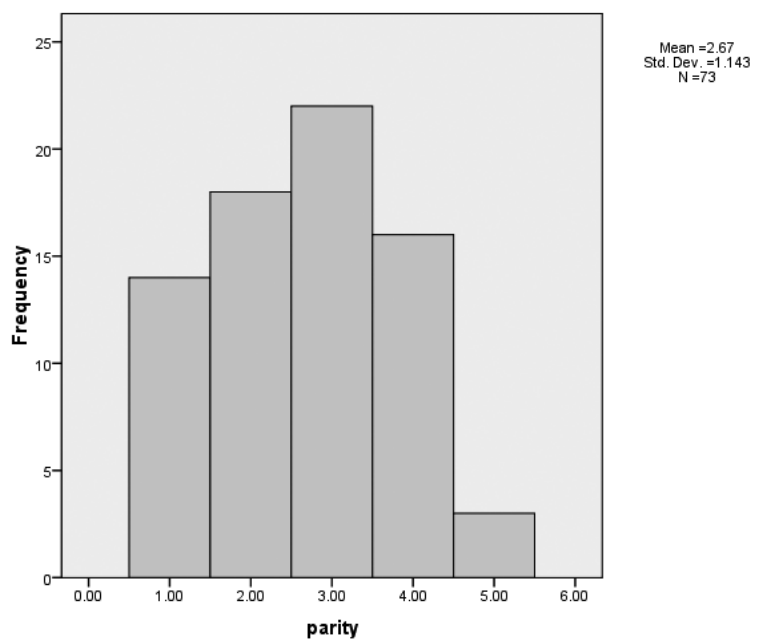

Figure-1. Show the frequency of parity among 73 pregnant women

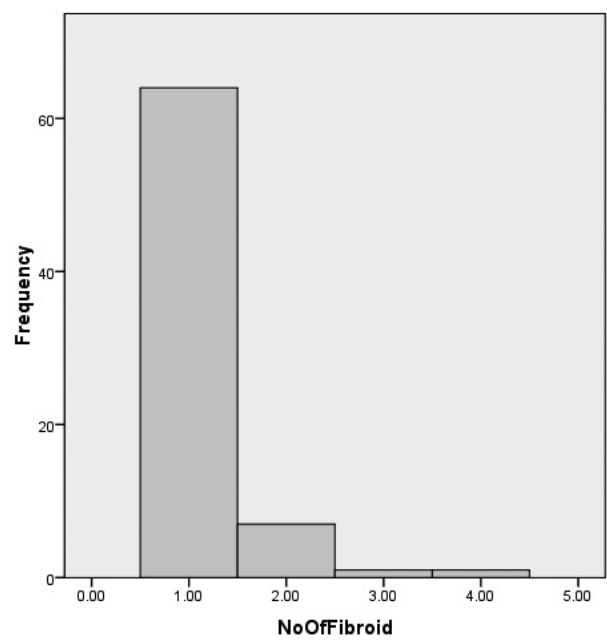

Figure-2. Number of fibroids

According to Figure-2 out of 73 patient, 64(87.7\%) patients had a single fibroid and $9(12.3 \%)$ patients had multiple fibroids.

\section{DISCUSSION}

Maitri Raghavendra et al indicated that leiomyoma is a disease that is most commonly seen in women of child bearing age. They are seldom found earlier than puberty and quit to develop after menopause. ${ }^{17}$ Begum $S$ et al described that multiparous women were found to own fibroids greater often than nulliparous in their perimenopausal years which indicates their characteristics slow development rate. ${ }^{18}$ The findings of our study also showed that fibroids are more common in multiparous women as compared to nulliparous/ primiparous. In contrast to this study, Radmila et al observed that leiomyoma are much more prevalent among nulliparous women as there is inverse relationship between myoma risk and parity. ${ }^{19}$ There is no widespread significance of the size, number, and kind of fibroids with incidence of unfavourable results. Saleh et al described in their study that there was no substantial distinction in adverse effects during pregnancy with single or multiple fibroids. ${ }^{20}$ Kempula et al found that most of the patient had unitary leiomyoma. ${ }^{21}$ In the present study, number of leiomyoma range from 1 to 4 and most of the patient had single fibroid. In contrast to a study by Begum $S$ who observed in their study that most of the patients had multiple fibroids. ${ }^{18}$ Shavell et al observed that a number of negative obstetric results have been associated with uterine fibroids. Large uterine fibroids > $5 \mathrm{~cm}$ cause delivery at an earlier gestational age and PPROM(Preterm premature rupture of the membrane) ${ }^{22}$ In our study we found that most of the fibroids were located on anterior wall of the uterus. This is analogous to the study of De Vivo et al, they observed that fibroids on anterior wall of the uterus were more common than any other site of the uterus. ${ }^{23}$ Shavell et al found in their study that most common location of fibroid is anterior wall of the uterus. ${ }^{22}$

\section{CONCLUSION}

The findings of this study concluded that the anterior wall of the uterus is more favorable for leiomyoma in pregnant women.

Copyright@ 02 May, 2020.

\section{REFERENCES}

1. Vilos GA, Allaire C, Laberge P-Y, Leyland N, Vilos AG, Murji $A$, et al. The management of uterine leiomyomas. Journal of Obstetrics and Gynaecology Canada 2015; $37(2): 157-78$.

2. Akinlaja OA. Uterine fibroids and pregnancy. Journal of Reproductive Biology and Endocrinology 2017; 1(1).

3. Stewart EA. Uterine fibroids. The Lancet 2001; 357(9252):293-8.

4. Navid S, Arshad S, Qurat ul A, Meo RA. Impact of leiomyoma in pregnancy. J Ayub Med Coll Abbottabad 2012; 24(1):90-2. 
5. Radhika B, Naik K, Shreelatha S, Vana H. Case series: Pregnancy outcome in patients with uterine fibroids. J Clin Diagn Res 2015; 9(10):QR01-4.

6. Williams AR. Uterine fibroids-what's new? F1000Research 2017;6.

7. Nkwabong E. An intramural uterine fibroid became submucosal in the puerperium-proposed probable mechanism: A case report. Journal of medical case reports 2018; $12(1): 88$.

8. Eze C, Odumeru E, Ochie K, Nwadike U, Agwuna K. Sonographic assessment of pregnancy co-existing with uterine leiomyoma in Owerri, Nigeria. Afr Health Sci 2013; 13(2):453-60.

9. Laughlin SK, Baird DD, Savitz DA, Herring AH, Hartmann $\mathrm{KE}$. Prevalence of uterine leiomyomas in the first trimester of pregnancy: An ultrasound screening study. Obstet Gynecol 2009;113(3):630-5.

10. Poovathi M, Ramalingam R. Maternal and fetal outcome in pregnancy with fibroids: A prospective study. Int J Sci Stud 2016; 3(11):169-72.

11. Abeshi S, Cl E, Ago B. Management outcome of uterine fibroids in pregnancy in a secondary health facility in calabar, South-South Nigeria. European Journal of Biology and Medical Science Research 2017; 5(1):1-8.

12. Lee HJ, Norwitz ER, Shaw J. Contemporary management of fibroids in pregnancy. Rev Obstet Gynecol 2010; 3(1):20-7.

13. Ibrar F, Riaz S, Dawood NS, Jabeen A. Frequency of fibroid uterus in multipara women in A Tertiary Care Centre in Rawalpindi. J Ayub Med Coll Abbottabad 2010; 22(3):155-7.

14. Abramowicz JS. Benefits and risks of ultrasound in pregnancy. Semin Perinatol 2013;37(5):295-300.
15. Eze J, Ugwu A, Ohagwu C, Ac I. The value of ultrasonography in the diagnosis of leiomyomas in Southeast Nigeria. 2013.

16. Noor S, Fawwad A, Sultana R, Bashir R, Qurat ul a, Jalil $\mathrm{H}$, et al. Pregnancy with fibroids and its and its obstetric complication. J Ayub Med Coll Abbottabad 2009; $21(4): 37-40$.

17. Kulkarni MR, Dutta I, Dutta DK. Clinicopathological study of uterine leiomyomas: A multicentric study in rural population. The Journal of Obstetrics and Gynecology of India 2016; 66(1):412-6.

18. Begum S, Khan S. Audit of leiomyoma uterus at Khyber Teaching Hospital Peshawar. Journal of Ayub Medical College Abbottabad 2004; 16(2).

19. Sparic R, Mirkovic L, Malvasi A, Tinelli A. Epidemiology of uterine myomas: A review. International journal of fertility \& sterility 2016; 9(4):424.

20. Saleh HS, Mowafy HE, Hameid AA, Sherif HE, Mahfouz EM. Does uterine fibroid adversely affect obstetric outcome of pregnancy? BioMed research international 2018; 2018.

21. Geethamala K, Murthy VS, Vani BR, Rao S. Uterine leiomyomas: An ENIGMA. Journal of mid-life health 2016; 7(1):22.

22. Shavell VI, Thakur M, Sawant A, Kruger ML, Jones TB, Singh M, et al. Adverse obstetric outcomes associated with sonographically identified large uterine fibroids. Fertility and sterility 2012; 97(1):10710.

23. De Vivo A, Mancuso A, Giacobbe A, Maggio Savasta $\mathrm{L}$, De Dominici $\mathrm{R}$, Dugo $\mathrm{N}$, et al. Uterine myomas during pregnancy: A longitudinal sonographic study. Ultrasound in Obstetrics \& Gynecology 2011; 37(3):3615.

\begin{tabular}{|c|l|l|l|}
\hline \multicolumn{3}{|c|}{ AUTHORSHIP AND CONTRIBUTION DECLARATION } \\
\hline Sr. \# & \multicolumn{1}{|c|}{ Author(s) Full Name } & \multicolumn{1}{|c|}{ Contribution to the paper } & Author(s) Signature \\
\hline 1 & Munaza Shahid & Corresponding author. & \\
\hline 2 & Hafiza lqra Kanwal & Author. & \\
\hline 3 & Sajid Shaheen Malik & Supervisor. \\
\hline 4 & Raham Bacha & Co-supervisor, Reviewer. \\
\hline
\end{tabular}

